\title{
The role of surgery in soft tissue sarcoma: Can we improve outcome and function towards sporting activities?
}

\author{
Reinhard Windhager (D) - Gerhard M. Hobusch
}

Received: 20 December 2019 / Accepted: 11 February 2020 / Published online: 9 March 2020

(C) The Author(s) 2020

\begin{abstract}
Summary Limb-sparing surgery with pre- or postoperative irradiation has evolved as the standard of care for local tumor control of soft tissue sarcoma while ablative procedures are applied in selected cases only. Adequate excision of sarcoma is prerequisite to guarantee local tumor control. While excision with wide margins has been educated in the past, tumor excision with closer margins has shown to provide similar local tumor control. Beside this oncological aspect, type of surgery and reconstruction impact the functional outcome after sarcoma excision in the extremities, which adds to quality of life for the patients. Satisfactory results have been shown by different scoring systems; however, more recent studies focus on high level activities like sports to define the efficacy of different procedures. This review focuses on recent developments within these two topics.
\end{abstract}

Keywords Soft tissue sarcoma - Margin - Local recurrence · Functional outcome · Sport activities . Surgical reconstruction $\cdot$ Tumor resection

\section{Background}

Soft tissue sarcomas (STS) are rare tumors of mesenchymal origin and account for roughly $1 \%$ of all adult malignancies [1]. Soft tissues sarcoma represent a very heterogeneous group of malignancies originating from the connective tissues with more than 50 histological subtypes [2]. The yearly incidence in Europe ranges between two and four new cases of STS per 100,000 people $[3,4]$. As the majority of STSs arise

\section{R. Windhager, MD $(\bowtie) \cdot G$. M. Hobusch}

Department of Orthopaedics and Trauma Surgery, Medical

University of Vienna, Währinger Gürtel 18-20, 1090 Vienna, Austria

reinhard.windhager@meduniwien.ac.at in the extremities and only $30 \%$ in the trunk, particularly in the retroperitoneum and $10 \%$ in the head and neck area, this review will focus only on soft tissue sarcomas in the extremities discussing the principle of local excision and the impact on local and systemic tumor control as well as new aspects in the functional outcome evaluation [5].

Diagnosis of STSs is often delayed due to the indolence of these palpable tumors, which can grow to a large extent until they cause discomfort and lead to consultation. Diagnosis is furthermore delayed by the fact that benign soft tissue tumors are hundredfold more frequent than STSs making distinction and clinical judgment difficult. Before treatment, exact diagnosis has to be established by core needle biopsy, preferably performed under ultrasoundguided imaging. The algorithm of diagnosis and treatment should always start with MRI as the method of choice followed by staging with chest CT or PET-CT after the diagnosis of sarcoma has been established (Fig. 1). There are several international, national and local institutions like the European Society for Medical Oncology-European Reference Network for rare adult solid cancers (ESMO-EURACAN) or the National Cancer Institute (NIH, Adult soft tissue treatment) providing practical guidelines in the treatment of STS [6-8]. Surgery has remained the mainstay in the treatment of STSs, despite significant progress in radiation and systemic targeted therapies. With the aim of local tumor control and satisfactory functional outcome, surgical treatment including microsurgical reconstruction using functional muscle and tendon transfers has changed significantly over the last few decades [9]. While amputation was the standard of care in the treatment of soft tissue sarcomas in the very beginning, this treatment has been substituted by limb-sparing surgery after evidence has been gained about the safety and effectiveness of this combined 
therapy by prospective randomized trials [10-12]. Limb-sparing surgery with simple local excision of soft tissue sarcoma was associated with a higher local recurrence rate compared to amputation if not combined with radiotherapy [13-16]. Radiation therapy can be applied either preoperatively or postoperatively [16]; however, discussion about advantages and disadvantages of these treatment modalities would exceed the scope of this review. Nevertheless, over the last three decades limb-sparing surgery with radiation therapy has become the standard of care in the treatment of localized soft tissue sarcomas, whereas amputation is carried out in less than $10 \%$.

\section{Surgical margins}

The concept of sarcoma resection has been widely influenced by the publications of Enneking et al. in the 1980s [17]. Their definition of surgical margins was based on the theory that the pseudocapsule as the outer layer of these tumors was surrounded by a reactive zone possibly containing tumor cells. Thus, they defined an adequate STS resection as an en bloc removal of the tumor with a healthy cuff of tissues covering this reactive zone. This type of adequate tumor resection was called wide resection, while marginal or intralesional margins touching the reactive zone or the tumor respectively were regarded inadequate. So-called radical resections removing the whole tumor-bearing compartment have been recommended for high-grade sarcomas; however, due to extra compartmental extension of these high-grade lesions this type of treatment is rarely applicable. Although widely used, the definition of wide margins has been questioned over the last two decades, leading to changes in the paradigm of soft tissue resection [18]. While definitions of margins in retrospective analyses varied significantly [19], those studies evaluating the width of resection margins are within the focus of this paper.

One of the first studies analyzing the width of resection margin in 111 patients after R0 resections showed better local tumor control in negative margins wider than $10 \mathrm{~mm}$ compared to margins less than $10 \mathrm{~mm}$, however, without any influence on overall survival [20]. Soon after this publication two studies analyzing all together 544 patients found out that negative margins more than $1 \mathrm{~mm}$ were adequate to improve a local control but again without any change in survival [21, 22]. In a more recent study, 235 patients were analyzed with respect to margins less than $1 \mathrm{~mm}$, between 1 and $5 \mathrm{~mm}$ and more than $5 \mathrm{~mm}$. There was no difference between these three subgroups with respect to local control and overall survival [23]. This finding was supported by another study analyzing 590 patients with R0 resected extremity soft tissue sarcomas showing that even a margin width of less than $1 \mathrm{~mm}$ had a similar favorable outcome when compared with wider margins $[24,25]$. However, the 5-year local recurrence-free survival in this analysis was lower com- pared to the other studies, while the 5-year diseasefree survival was similar.

Although there is more evidence that margins of about $1 \mathrm{~mm}$ is sufficient for local tumor control, it is unclear and discussed extensively whether the quality of resection has an impact on survival representing an independent factor such as grade, size and depth. While in one of the largest series of soft tissue sarcomas an association between surgical margin and survival could be established $[5,11,26]$, other studies pointed out contradictory findings without any association between margin's status and survival [27]. Because of this contradiction several authors point out that the positive margin's status maybe regarded rather as a result of the aggressiveness of the tumor biology with a higher potential to metastasize than a failure of surgical technique.

\section{Functional evaluation}

Wide tumor resections can lead to decreased function and disability due to major tissue defects and long-term survivors of musculoskeletal tumors therefore become less physically activity, which results in a reduced state of health [28, 29]. Assi et al. pointed out the importance of the prescription of post- and even preoperative physical activity to improve QOL in patients after lower extremity sarcoma [29]. Numerous literature examples demonstrate the usage of clinician reported functional outcomes (CROMS), such as the Musculo-Skeletal Tumor Society Score (MSTS) after treatment of STS [30]. Only a few studies report on patient-reported outcomes after treatment of sarcomas, e.g., the Toronto Extremity Salvage Score (TESS) [31].

The long-term MSTS outcomes range between 77 and 100, while the long-term TESS outcomes range between 86 and 100 [30, 32]. More recently sports activity, as a complex functional leisure activity, has been used to serve as patient-reported outcome measure after STS treatment. According to this case series patients after STS treatment reported a mean possible workout time of about $4 \mathrm{~h} /$ week in the long-term, as well as a UCLA sports activity level of about $8 / 10$. The UCLA Measurement shows good correlations with already existing MSTS as well as TESS scores. Sports may be important in many patients' lives for the majority of sarcoma patients and it turns out that apart from biking, jogging, swimming as well as gymnastic exercise, some patients are still able to participate in high-impact sports such as running, soccer, tennis, and skiing as shown in later follow-up assessments.

However, deep muscle-resections decreased high active sports to $43 \%$ activity compared to $82 \%$ of patients after superficial tumors. As a consequence more patients start to participate in low-impact sports to compensate for high-impact activities prior to surgery [32]. 
Fig. 1 Algorithm for the treatment of soft tissue sarcoma (STS) of the extremities. CT computed tomography, $R T X$ radiation therapy

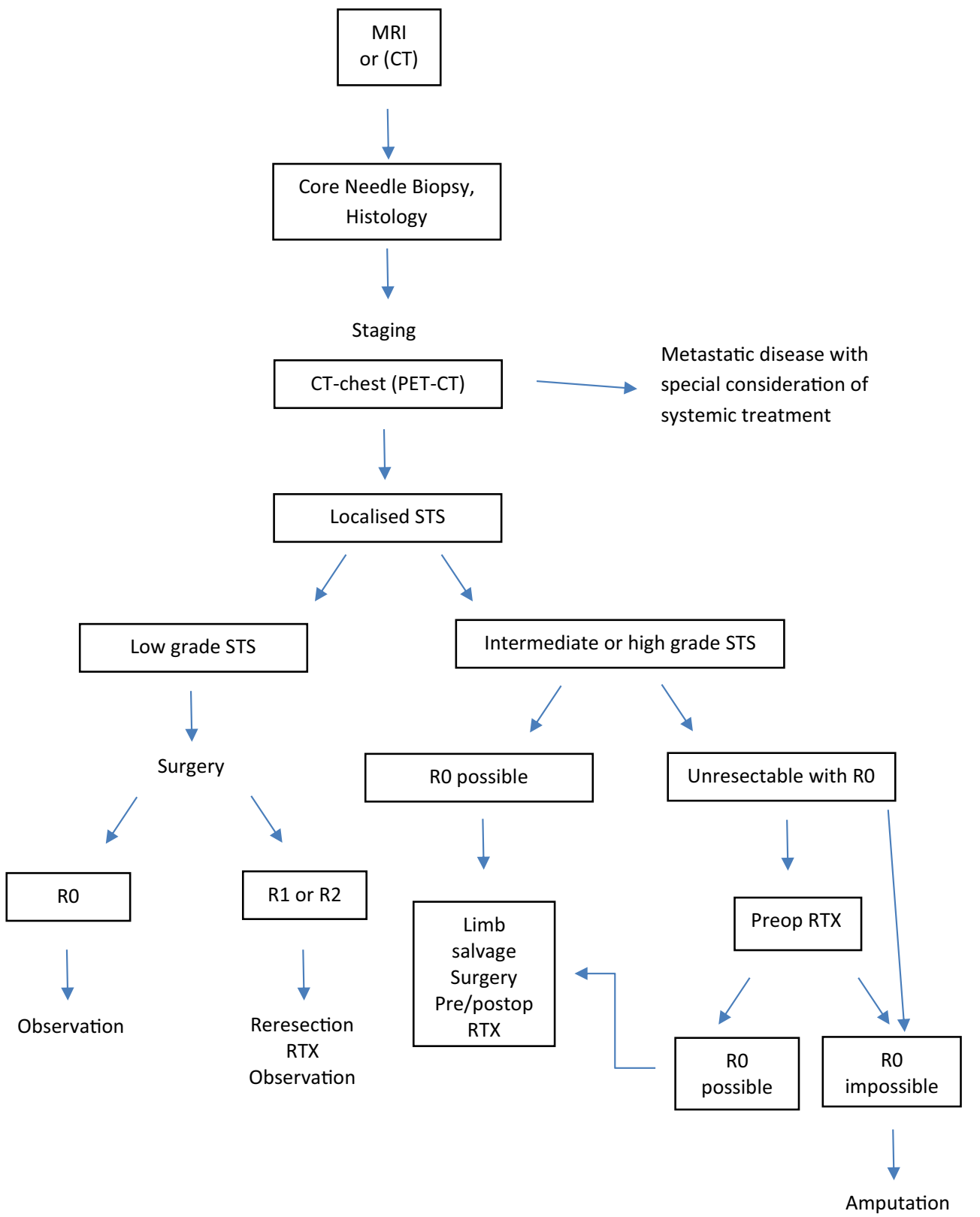

Several authors proclaim differences in activity depending on the location of sarcomas and resected muscle groups respectively [30, 32]. There is agreement on less favorable results after resection of the lateral vastus muscle and gastrocnemius muscle with UCLA activity levels of 7/10 being reached. However, diverse functional outcomes after biceps femoris resection and other muscles were reported. The tumor site obviously plays a role in postoperative mobility and reasons for outcome discrepancies between afflicted muscle groups may be found in underpowered study designs as well as differences regarding individual adaptation skills to certain resections.

A major limitation in most of the cross-sectional studies lies in fact that functional data up to now is not used as an individual continuous measure to express individual functional development. Furthermore functional data often show large variance indicating the presence of different functional outcomes in many patients. A recent literature review concludes that although PROMs are used in clinical studies of STS, they are not specific and may not capture the unique needs of this population [33]. However, the assessment of outcome data including qualitative research is critically important to better understand the needs of soft tissue sarcoma patients. Furthermore, the implementation of preliminary pre- and postoperative physical activity recommendations are equally important [29]. It is necessary to draw attention to this topic to improve individualization of patient care, to precisely shape patients' expectations and to improve the individual outcome. 


\section{Take-home message}

Resection of soft tissue sarcomas of the extremities with clear margins in combination with pre- or postoperative radiation therapy provides excellent local tumor control and satisfactory functional outcome. As a prerequisite the algorithm for diagnosis and staging and correctly performed biopsy has to be carefully followed.

Funding Open access funding provided by Medical University of Vienna.

Conflict of interest R. Windhager receives honoraria from Stryker, CeramTec, Johnson \& Johnson (Institutional/Educational Support), Stryker GmbH (Consulting Agreement), Johnson \& Johnson (Royalties). G.M. Hobusch declares that he has no competing interests.

Open Access This article is licensed under a Creative Commons Attribution 4.0 International License, which permits use, sharing, adaptation, distribution and reproduction in any medium or format, as long as you give appropriate credit to the original author(s) and the source, provide a link to the Creative Commons licence, and indicate if changes were made. The images or other third party material in this article are included in the article's Creative Commons licence, unless indicated otherwise in a credit line to the material. If material is not included in the article's Creative Commons licence and your intended use is not permitted by statutory regulation or exceeds the permitted use, you will need to obtain permission directly from the copyright holder. To view a copy of this licence, visit http://creativecommons.org/licenses/by/4.0/.

\section{References}

1. Jemal A, Siegel R, Ward E, Murray T, Xu J, Thun MJ. Cancer statistics, 2007. CACancer JClin. 2007;57(1):43-66.

2. Fletcher CDM. The evolving classification of soft tissue tumours-an update based on the new 2013 WHO classification. Histopathology. 2014;64(1):2-11.

3. Mastrangelo G, Coindre J-M, Ducimetière F, Dei Tos AP, Fadda E, Blay J-Y, et al. Incidence of soft tissue sarcoma and beyond: a population-based prospective study in 3 European regions. Cancer. 2012;118(21):5339-48.

4. Wibmer C, Leithner A, Zielonke N, Sperl M, Windhager R. Increasing incidence rates of soft tissue sarcomas? A population-based epidemiologic study and literature review. Ann Oncol. 2010;21(5):1106-11.

5. Stojadinovic A, Leung DHY, Hoos A, Jaques DP, Lewis JJ, Brennan MF. Analysis of the prognostic significance of microscopic margins in 2,084 localized primary adult soft tissue sarcomas. Ann Surg. 2002;235(3):424-34.

6. Casali PG, Abecassis N, Aro HT, Bauer S, Biagini R, BielackS, et al. Soft tissue and visceral sarcomas: ESMO-EURACAN Clinical Practice Guidelines for diagnosis, treatment and follow-up. Ann Oncol. 2018;29(Suppl4):iv268-iv9.

7. National Cancer Institute. Adult Soft Tissue Sarcoma Treatment (PDQ $\left.{ }^{\circledR}\right)-H e a l t h$ Professional Version. 2019. https://www.cancer.gov/types/soft-tissue-sarcoma/hp/ adult-soft-tissue- treatment-pdq. Accessed 25Jan 2020.

8. Medscape, editor. Soft tissue sarcoma treatment protocols: treatment protocols. 2019. https://emedicine.medscape. com/article/2007168-overview?src=emailthis. Accessed 27 Jan 2020.

9. MacArthur IR, McInnes CW, Dalke KR, Akra M, Banerji S, Buchel EW, et al. Patient reported outcomes following lower extremity soft tissue sarcoma resection with microsurgical preservation of ambulation. J Reconstr Microsurg. 2019;35(3):168-75.

10. Rosenberg SA, Tepper J, Glatstein E, Costa J, Baker A, Brennan M, et al. The treatment of soft-tissue sarcomas of the extremities: prospective randomized evaluations of (1) limb-sparing surgery plus radiation therapy compared with amputation and (2) the role of adjuvant chemotherapy. Ann Surg. 1982;196(3):305-15.

11. Pisters PW, Leung DH, Woodruff J, Shi W, Brennan MF. Analysis of prognostic factors in 1,041 patients with localized soft tissue sarcomas of the extremities. J Clin Oncol. 1996;14(5):1679-89.

12. Yang JC, Chang AE, Baker AR, Sindelar WF, Danforth DN, Topalian SL, et al. Randomized prospective study of the benefit of adjuvant radiation therapy in the treatment of soft tissue sarcomas of the extremity. J Clin Oncol. 1998;16(1):197-203.

13. LeibelSA, Tranbaugh RF, Wara WM, Beckstead JH, BovillEG, Phillips TL. Soft tissue sarcomas of the extremities: survival and patterns of failure with conservative surgery and postoperative irradiation compared to surgery alone. Cancer. 1982;50(6):1076-83.

14. Markhede G, Angervall L, Stener B. A multivariate analysis of the prognosis after surgical treatment of malignant softtissue tumors. Cancer. 1982;49(8):1721-33.

15. Gerner RE, Moore GE, Pickren JW. Soft tissue sarcomas. Ann Surg. 1975;181(6):803-8.

16. Leachman BK, Galloway TJ. The role for radiation therapy in the management of sarcoma. Surg Clin North Am. 2016;96(5):1127-39.

17. Enneking WF, Spanier SS, Malawer MM. The effect of the anatomic setting on the results of surgical procedures for soft parts sarcoma of the thigh. Cancer. 1981;47(5):1005-22.

18. Gronchi A, Casali PG, Mariani L, Miceli R, Fiore M, Lo Vullo $\mathrm{S}$, et al. Status of surgical margins and prognosis in adult soft tissue sarcomas of the extremities: a series of patients treated at a single institution. J Clin Oncol. 2005;23(1):96-104.

19. Trovik CS, Skjeldal S, Bauer H, Rydholm A, Jebsen N. Reliability of margin assessment after surgery for extremity soft tissue sarcoma: the SSG experience. Sarcoma. 2012; https://doi.org/10.1155/2012/290698.

20. McKee MD, Liu DF, Brooks JJ, Gibbs JF, Driscoll DL, Kraybill WG. The prognostic significance of margin width for extremity and trunk sarcoma. J Surg Oncol. 2004;85(2):68-76.

21. Dickinson IC, Whitwell DJ, Battistuta D, Thompson B, Strobel N, Duggal A, et al. Surgical margin and its influence on survival in soft tissue sarcoma. ANZ J Surg. 2006;76(3):104-9.

22. Kainhofer V, Smolle MA, Szkandera J, Liegl-Atzwanger B, Maurer-Ertl W, Gerger A, et al. The width of resection margins influences local recurrence in soft tissue sarcoma patients. EurJSurg Oncol. 2016;42(6):899-906.

23. Ahmad R, Jacobson A, Hornicek F, Haynes AB, Choy E, Cote $\mathrm{G}$, et al. The width of the surgical margin does not influence outcomes in extremity and truncal soft tissue sarcoma treated with radiotherapy. Oncologist. 2016;21(10):1269-76.

24. Harati K, Goertz O, Pieper A, Daigeler A, Joneidi-Jafari H, Niggemann $H$, et al. Soft tissue sarcomas of the extremities: surgical margins can be close as long as the resected tumor has no inkon it. Oncologist. 2017;22(11):1400-10.

25. Harati $\mathrm{K}$, Lehnhardt M. The changing paradigm of resection margins in sarcoma resection. Innov Surg Sci. 2017;2(4):165-70. 


\section{short review}

26. Pisters PW, Harrison LB, LeungDH, WoodruffJM, CasperES, Brennan MF. Long-term results of a prospective randomized trial of adjuvant brachytherapy in soft tissue sarcoma. JClin Oncol. 1996;14(3):859-68.

27. Eilber FC, Rosen G, Nelson SD, Selch M, Dorey F, Eckardt J, et al. High-grade extremity soft tissue sarcomas: factors predictive of local recurrence and its effect on morbidity and mortality. Ann Surg. 2003;237(2):218-26.

28. Wampler MA, Galantino ML, Huang S, Gilchrist LS, Marchese VG, Morris GS, et al. Physical activity among adult survivors of childhood lower-extremity sarcoma. J Cancer Surviv. 2012;6(1):45-53.

29. Assi M, Ropars M, Rébillard A. The practice of physical activity in the setting of lower-extremities sarcomas: a first step toward clinical optimization. Front Physiol. 2017;8:833.

30. Gerrand CH, Wunder JS, Kandel RA, O'Sullivan B, Catton CN, Bell RS, et al. The influence of anatomic location on functionaloutcomeinlower-extremity soft-tissuesarcoma. Ann Surg Oncol. 2004;11(5):476-82.

31. Davis AM, Wright JG, Williams JI, Bombardier C, Griffin A, Bell RS. Development of a measure of physical function for patients with bone and soft tissue sarcoma. Qual Life Res. 1996;5(5):508-16.

32. Hobusch GM, Cernakova M, Puchner SE, Kolb A, Panotopoulos J, Windhager R. Sports activity after soft tissue sarcoma of the lower extremity. Disabil Rehabil. 2020;42(1):14-9.

33. Winnette R, Hess LM, Nicol SJ, Tai DF, Copley-Merriman C. The patient experience with soft tissue sarcoma: a systematic review of the literature. Patient. 2017;10(2):153-62.

Publisher's Note Springer Nature remains neutral with regard to jurisdictional claims in published maps and institutional affiliations.

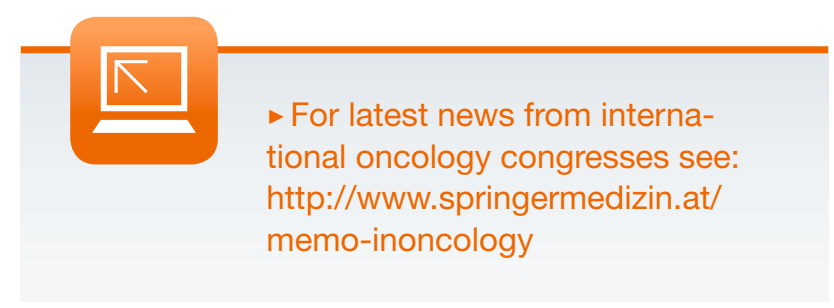

